Yayın Geliş Tarihi: 11.07.2019

Yayına Kabul Tarihi: 06.08.2019

Online Yayın Tarihi: 25.09.2019

http://dx.doi.org/10.16953/deusosbil.590565
Dokuz Eylül Üniversitesi

Sosyal Bilimler Enstitüsü Dergisi

Cilt: 21, Say1: 3, Y11: 2019, Sayfa: 787-804

ISSN: 1302-3284 E-ISSN: 1308-0911

Araştırma Makalesi

\title{
KAM SPIKER TÜRLERİ AÇISINDAN GENEL KANALLAR İLE HABER KANALLARI KARŞILAŞTIRMASI
}

$\ddot{O} z$

Gökmen Hakan KARADA $\breve{G}^{*}$

Bu çalışmanın amacı televizyon kanallarının izlenme oranı (rating) yarışının haberlerin sunum şekillerinden biri olarak kam spiker tercihlerine etkisini araştırmaktır. Çalışma, izlenme oranı baskısının televizyon haber editörlerini daha sansasyonel bir tarza sevk edip etmediğini, sevk ediyorsa bunun derecesini ortaya çıkarmak bakımından önem taşımaktadır. TV haberciliği literatüründe kam spiker'ler ü̧̈ türde sinıflandırılabilir: doğrudan ve sert girişli kam spiker (hard lead), dolayl girişli ve merak uyandıran kam spiker (soft lead), çarpıcı bir alıntıyla başlayan kam spiker (quote lead). Bu kam spikerlerden hangisinin ne oranda kullanılacağına ilişkin editoryal karar alırken çeşitli kriterler göz önünde tutulur: kanalın türü, yayın kuşağının türü, haberin türü. Çalışmada Türkiye'de genel TV kanalları ile tematik haber kanalları arasında kam spiker türü tercihi ve kullanım ăgırlı̆̆ karşılaştırmalı olarak incelenmektedir. Genel TV kanalları olarak Show, Star ve ATV; haber kanallarl olarak da NTV, Haber Global ve HaberTürk'ün ana haber bültenlerinin içerik analizi yapılmıştır. Görece daha yoğun "izlenme oranı baskısı" altında çalışan genel kanalların ana haber bültenlerinde, tematik haber kanallarının ana haber bültenlerine göre 'dolayl ve merak uyandıran kam spiker'lerin daha fazla tercih edilmesi beklenebilir. Çalışmanın sonuçları bu varsayımı desteklemiştir.

Anahtar Kelimeler: Kam Spiker, Genel Kanal, Haber Kanal, Televizyon Haberi.

\section{COMPARISON OF GENERALIST TV AND NEWS TV IN TERMS OF TV NEWS LEAD TYPE}

\section{Abstract}

This study aims at research of effects of rating competition of television channels on news lead choices as a news presentation style. The importance of the study is to determine whether rating pressure leads editors to a more sensational style, and if so, how strong this tendency is. In broadcast announcing leads can be classified in 3 types: hard leads, soft leads and quote leads. When making editorial decisions on which of them and how much to use,

Bu makale için önerilen kaynak gösterimi (APA 6. Sürüm):

Karadağ, G. H. (2019). Kam spiker türleri açısından genel kanallar ile haber kanalları karşılaştırması. Dokuz Eylül Üniversitesi Sosyal Bilimler Enstitüsü Dergisi, 21 (3),787-804.

* Dr. Öğr. Üyesi, İstanbul Aydın Üniversitesi, İletişim Fakültesi, Yeni Medya ve İletişim Bölümü, ORCID: 0000-0002-6087-4098, gokmenkaradag@gmail.com 
there are some criteria to be considered: type of television channel, type of slot, type of news. In this study news lead choices and use rates are analyzed comparatively between generalist channels and news channels in Turkey. Content analysis of night newscasts of Show, Star, ATV (as generalist channels) and NTV, Habertürk, Haber Global (as news channels) was accomplished. Generalist channels under heavy rating pressure are expected to give more place for soft leads in their newscasts compared to thematic news channels. The results of this study supported this thesis.

Keywords: Television News Lead, Generalist Channel, News Channel, Television News.

\section{GİRIŞ}

TV yayıncılığının rekabet kulvarlarının önemli bir ayağını haberler oluşturur. Diziler, sabah kuşakları, kadın kuşakları, yarışma programları, eğlence programları ve şovlarda izlenme oranı (rating) yarışına giren kanallar ana haber bültenleri ve haber programlarında da birbirlerine üstünlük sağlamak için haber kadrolarına ve sunucularına (anchor'larına) yatırım yapmakta ve haber sunum şekillerini önemsemektedirler. Özellikle ana haber bültenleri, "prime time"da yani ekran başında en çok izleyicinin bulunduğu bir zaman diliminde yayımlandığı ve bu zaman dilimi reklam veren için büyük önem taşıdığı için kanallar arası rekabet daha da kızışmaktadır. Bu rekabetin haber bültenlerine biçim ve içerik olarak yansıdığg boyutlardan biri de haberin sunum metnidir.

Kam spiker denilen bu metnin tarzı, içeriği ve anlatım yapısı, haberin izleyiciyle kurduğu bağı etkileyebilmektedir. Görece daha yoğun "izlenme oranı baskısı" altında çalışan genel kanalların ana haber bültenlerindeki kam spikerlerin, tematik haber kanallarının ana haber bültenlerindekilere oranla daha dikkat çekici ve merak uyandırıcı olması beklenebilir. Bu editoryal tercih genel kanalların tematik kanallara oranla daha sansasyonel bir sunum peşinde olduğunun tezahürü sayılabilir. Ayrıca belli haber türlerinin, merak uyandıran ve dikkat çeken kam spikerler için daha uygun bir materyal oluşturduğu da söylenebilir. Bu çalışmada bu varsayımların Türkiye televizyon yayıncılığg sektöründe fiili duruma ne ölçüde yansıdığg incelenmektedir.

Kullanımlar ve doyumlar kuramına göre televizyon izleyicileri belli psikolojik ihtiyaçlarını televizyon ekranına taşımaktadır (Parsa, 1993: 146). İnsanların kitle iletişim araçlarıyla giderdikleri ihtiyaç grupları içinde enformasyonun yanı sıra zevk alma ve kaçış da bulunmaktadır (Katz vd., 1973: 166). İzleyici tercihleri ve onun doğrudan ifadesi olan rating'ler konusunda belli ölçüde teorik kavrayışa ve büyük ölçüde saha birikimine sahip olan televizyon içerik üreticileri de farkında olarak ya da olmayarak bu ihtiyaçlara hitap eden içerikler üretmektedirler. Televizyon yayıncılığının tarihi içinde haberlerin ve haber programlarının giderek tabloid tarza ve habeğlence (infotainment) tarzına dönüşmesi de bu minvalde gerçekleşmiştir (Karadağ, 2000: 76-80). 
İzleyicilerin aradıkları doyumları karşılamak için televizyon habercilerinin benimsediği sansasyonel tarz, haberin sunum şeklinde de kendini göstermektedir. Her kam spikerde kaşınan bir merak duygusu, ardından bu merakın giderilmesi ve bu serinin bültendeki pek çok haber için devam etmesi, izleyicileri, bir gerçekler ve olgular bütününü izlemekten ziyade bir gösteri izleme durumuna sokabilir.

$\mathrm{Bu}$ çalışma izlenme oranlarını artırabilmek için haberin daha çarpıcı bir şekilde sunumu eğiliminin Türkiye'de genel televizyon kanalları ile tematik haber kanallarına ne ölçüde yansıdığını karşılaştırmalı olarak araştırmaktadır. Bu karşılaştırma izlenme oranı baskısının televizyon haber editörlerini daha sansasyonel bir tarza sevk edip etmediğini, sevk ediyorsa bunun derecesini ortaya çıkarmak bakımından önem taşımaktadır. Karşılaştırma televizyonların ana haber bültenlerindeki kam spiker'lerin içerik analizi üzerinden yapılmaktadır. Türkçe literatürde kam spiker türleriyle ilgili bu yönde bir çalışmaya rastlanmamıştır.

\section{ANA HABER BÜLTENLERINIIN TV KANALLARI IÇIN ÖNEMI VE IŞLEVI}

Ulusal, uluslararası ve yerel; güncel, toplumsal, siyasal, kültürel, ekonomik olay, konu ve gelişmelerin önem sırası gözetilerek sunulduğu ana haber bültenleri genel olarak, izleyicinin ekran başında en çok bulunduğu saatlerde kapsamlı bir şekilde izleyiciyle buluşur (Uğurlu, 2012: 49). Ana haber bülteni "prime time"da yayımlanan dizi ya da şovlara göre daha düşük maliyetlidir ve haber izleyicisi reklam veren için caziptir (Postman \& Powers, 1996: 13-14). Ancak konunun karlılığın ötesinde boyutları da bulunmaktadır. Bir kanalın ana haberdeki izlenme oranı başarısı hem kanalın genel olarak "prime time" performansını etkilemekte hem de etkinliğini ve gücünü artırmaktadır (Uğurlu \& Öztürk, 2006: 62). Ana haber bültenleri, televizyonların bayrak gemileridir (Sağnak, 2011: 75). Bu durum en çok genel kanallar için geçerli olsa da haber kanallarını da etkilemektedir.

Genel yayın kanalları ve tematik kanallar için çeşitli tanımlar mevcuttur. Genel kanal, spesifik tematik içeriği olmayan genel eğlence kanalı olarak; tematik kanalsa, belli bir tür programlamada uzmanlaşan spesifik bir türe veya konuya adanmış ve spesifik bir hedef kitleye yönelmiş TV kanalı olarak tanımlanmaktadır (Akt. Karadağ ve Algül, 2018: 709). Ana haber yarışı, genel kanallar arasında çok daha görünür olsa da tematik haber kanalları arasında da sürmektedir. Haber kanalları gün boyu haber vermelerine rağmen ana haber bülteni de hazırlamaktadır.

ABD'de pek çok televizyon kanalı bir kısmı 30 dakika, diğerleri bir saat süren, akşam 10.00 ya da 11.00 'de yayımlanan günlük iki veya üç haber program üretir (Hyde \& Ibrahim, 2016: 162). Amerikan şebeke kanallarında (CBS, NBC ve $\mathrm{ABC}$ ) yerleşmiş akşam haberlerine ayrılan süre 30 dakikadır (Kars, 2013: 164). TV akşam haber bültenleri dünyanın her yanında birinci kuşak yayın saatlerinde izleyici sayısının en fazla olduğu saat diliminde yayına girmekte 15 dakika, yarım saat ya da 1 saat süreyle devam etmektedir (Parsa, 1993: 25). Türkiye'de televizyon ana haber 
bültenleri "prime time" televizyonlarında, hemen aynı saatte, yaklaşık 45 dakikada, ortalama uzunluğu iki dakikayı bulan birçok haberi kapsamaktadır (Sağnak, 2011: 73).

Televizyon haberlerinde asıl sunum biçim sürekli konuşmadır: spiker haberi okur, karşılıklı görüşmeler yapılır, sorular sorulur, canlı bağlantılar yapılır, stüdyoya konuk çağrılır (Kars, 2013: 155). Ana haber bültenleri haberi hikâyeleştirerek izleyicilerle bir diyalog halinde sunar. Aslında ana haber bülteninde yaşanan şey tarzları, görünüşleri ve kişilikleriyle etki yaratan anchor'lar, muhabirler ve izleyici arasında bir diyalogdur (Cramer vd., 1996: 84).

\section{TV HABER METINLERININ ÖZELLİKLERİ}

XX. yüzyılda radyo ve televizyon gibi iki yeni kitle iletişim aracinın gazeteler yanında etkinlik kazanması haber dilini değiştirmiş, haber yazma kuralları radyo ve televizyonun yapısal özelliklerine göre uyarlanmıştır (Tokgöz, 1994: 297). Kitle iletişiminin yeni habercilik modeli olan televizyon gazeteciliği; radyo haberciliği, yazılı basının röportaj teknikleri ve film tekniklerinin bir sentezidir (Cereci, 2001: 157). TV metni net ve basit olarak yazılmalıdır ve ifadeler sıradan insanları hedeflemelidir (White \& Barnas, 2010: 102). Yazılı ifade anlaşılmadığında tekrar okunabilir ancak videoda izleyicinin kavramak için tek bir şansı olacaktır (Heist, 2013: 179). Dinleyicilerin haberdeki bilgiyi duydukları veya gördükleri anda anlayabilmeleri için metnin, yazılı basında olduğu gibi göz için değil kulak için yazılması gerekir (Telg, 2018: 1). Gözden ziyade kulak için yazmak olarak ifade edilen tarz, konuşma tarzıyla yazarak sağlanır (Stephenson vd., 2009: 150). Radyoda da televizyonda da geçerli olan bu tarz, haberi dinleyen ya da izleyen insanlarla konuşuyormuş gibi yazma temeline dayanır (Vural, 2012: 151). Karmaşık bir cümle yapısı hem metni seslendirecek sunucu için okuma zorluğuna neden olur hem de izleyicinin söylenmek istenen şeyi kavramasını güçleştirir (Kapakl1, 2010: 82). Haber gazetede yazılır, radyoda okunur, televizyonda ise anlatılır (Kaptan, 1999: 79).

Televizyon haberciliğinde bülten süreleri kısıtlı olduğu için haberler geniş ayrıntılarıyla ele alınamaz (Cereci, 2001: 158; Parsa, 1993: 25). Çok fazla olguyu kapsayan bir haberi bir seferde anlamak zor olacaktır (Stephenson vd., 2009: 151). Televizyon haberi çok fazla bilgiyle şişirilmemeli, haber metninin paragrafları ve cümleleri kısa olmalıdır: en fazla 4-5 cümlelik paragraflar ve en fazla 15-16 sözcüklük cümleler (Dileklen, 2005: 100). Bu limitlerin daha aşağısını savunanlar da vardır: İdeal olarak 6-7 sözcükten, en fazla 8-9 sözcükten ibaret cümleler (Sağnak, 2011: 143).

TV haberlerinde haber içeriğini anlatan metin dili ile olayı gösteren görüntü dilinin birbiriyle tutarlı olması gerekmektedir (Vural, 2012: 150). Üst ses ya da perfore olarak da adlandırılan bu metin, görüntülerin iletmediği bilgi boşluklarını doldurmalı ve programa ek değer katmak için ekstra materyal katkısında 
bulunmalıdır (Chapman \& Kinsey, 2009: 111). Görüntü sözle tekrar edilmemeli, görüntü olayı anlatmalı, sözcüklerse olay hakkında bilgi vermek için kullanılmalıdır (Kaptan, 1999: 80). İzleyicilere zaten gördüklerini anlatmaktansa görüntülerin ortaya çıkarmadığı veya çıkaramadığı şeyleri anlatarak video desteklenmelidir (White \& Barnas, 2010: 207). Metin ekranda gösterilenleri netliğe kavuşturmalı, bir bağlama oturtmalı ve açıklamalıdır (Boyd, 2001: 345). Örneğin haber, kayalıklardaki bir tanker çekimleriyle başlıyorsa, "Gemi kayalıklarda enkaza dönüştü..." yerine "Elli bin ton ham petrol yüklü Panama bandıralı tanker..." diye yazilmalidır (Thompson, 2005: 128).

Yazılı basında haberlerin piramit tarzında yazılması çok eski bir gelenektir. Televizyon haberinin de piramit tarzında yazılması gerektiğini savunanlar olduğu kadar televizyon haber metnine farklı bakanlar da bulunmaktadır. Televizyon haber metninin de haberin en önemli noktalarını özet bir giriş cümlesiyle sunması ve kalan detayları önemine göre azalan bir düzen içinde sunması gerektiği dile getirilmektedir (Stephenson vd., 2009: 151). Ancak televizyon haberleri doğrusal bir biçimde de düşünülebilir. Haber dikkat çekerek başlar, hızla ilgi yükseltilir, bir kapanışa ya da sonraki bölümde neler olacağıyla ilgili bir soruya doğru ilerler (Thompson, 2005: 113).

\section{TV HABER METINLERININ BÖLÜMLERİ: KAM SPIKEER VE PERFORE}

Televizyonların haber bültenlerinde temel olarak üç çeşit haber sunumu gerçekleştirilir: 1) Çoğunlukla son dakika haberlerinde kullanılan, görüntüyle desteklenmeyen, sadece sunucunun kameraya okuduğu stüdyo haber (STD); 2) Sunucunun, haberin girişini kameraya okuduktan sonra ekrana gelen görüntü üzerine stüdyoda yayın sırasında seslendirme yaptığı DSF (doğal ses fonda) haber; 3) Sunucunun girişi okumasının ardından haber bandının yayına girdiği paket, beta, VTR veya sesli haber denilen haber (Sağnak, 2011: 150-154). Beta ve VTR terimleri kısaltmalardır: Beta, elektronik haberciliğin önemli bir donanımı olan Betacam ses, görüntü, kayıt formatının kısaltılmışıdır; VTR de Video Tape Recorder'ın (video bant kaydedici) kısaltmasıdır. Televizyon haberinde sunucunun kameraya okuduğu bölüme ise Kam SPK denilmiştir ve bu terim de bir reji komutu olan "Kamera Spikerde"nin kısaltılmış halidir. Paket haberde sunucunun kam spikeri okuduktan sonra yayına giren videonun metnine ise perfore ya da üst ses (V/O yani voice over) denilmektedir.

Gazete, radyo ve televizyon haberlerinin girişi için ortak noktalar olduğu gibi ayırt edici unsurlar da bulunmaktadır. Girişte, tek bir odak noktası, tek bir baskın nokta vurgulanır, sonra giriş onu izleyen cümlelerle desteklenir ve genişletilir (Fang, 1991). Girişler, televizyonda, gazeteler dünyasındaki anlamlarından biraz farklıdır. Amerikan yayıncılık geleneğinde "lead" veya "cue" denilen giriş (bizde kam spiker) bir sunucu tarafindan okunur ve bir haberi veya canlı röportajı tanitır (Thompson, 2005: 101). Yani yazılı basın haberciliğinde okurun haberle ilgilenmesini sağlayan 
başlık, üst başlık, alt başlık, spot gibi ifadelerin (Girgin \& Özay, 2013: 88-89) işlevini, televizyon haberciliğinde kam spiker ve perforenin ilk kısmı görmektedir.

Her haberin bir giriş bölümü ve bunu izleyen gövde diye adlandırılan diğer bölümleri bulunur (Tokgöz, 1994: 181). Haberin girişi, haberi tanıtan, önem ve ilginçliğini vurgulayan bölümken gövde ise habere ilişkin bilgilerin daha detaylı olarak belirtildiği ve ek bilgilerle geliştirildiği bölümdür (Uyguç \& Genç, 1998: 121). Giriş denilince kabul gören anlayış daha çok zaman dizimsel bir anlatımdır oysa televizyon haber metninde zaman dizimsel sürece müdahale edilir (Aslan, 2002: 147-148). Televizyon haberinde bu bölümleme kam spiker ve perfore olarak adlandırılır. Bu iki metni bir bütün olarak ele almak gerekir. Aksi takdirde kam spiker'i, perfore metninin ilk satırlarında tekrar etmek gibi bir hataya düşülür ki televizyon haberlerinde buna sık rastlanır (Trewin, 2003: 80). İyi yazılmış bir kam spiker haberin özünü yakalamalı, konuşma diliyle yazılmalı ve haberin en önemli gerçeklerini içermelidir (Abrahamsen, 2017). İdeal olarak 3 ila 6 satırlık kam spiker, vurucu ve haberin algılanmasını sağlayacak nitelikte olması gerekir (Sağnak, 2011: 150). Kam spiker izleyiciyi gelmekte olana hazırlamanın yoludur (Boyd, 2001: 343).

Haber girişinin bütün $5 \mathrm{~N} 1 \mathrm{~K}$ sorularına (kim, ne, nerede, ne zaman, neden ve nasil) cevap vermesi, geçmişi çok eskiye dayanan bir beklenti de olsa hala bazı gazete editörlerince savunulmaktadır. Ancak televizyon yayıncılığında bu kural işlemez. Kam spiker ve perfore bir bütün olarak ele alınır ve soruların tamamı ancak haber bittiğinde yanıt bulur (White \& Barnas, 2010: 131). Coğunlukla haberin flaşında ne sorusunun yanıtı yer almalıdır. Niçin ve nasıl olduğu ise gövde bölümünde yanıtlanarak yazılır (Uyguç \& Genç, 1998: 122; Fang, 1991).

\section{KAM SPIKER TÜRLERİ VE KULLANIM ALANLARI}

Kam spiker haberin en önemli unsurudur. Gelmekte olanların tonunu belirlemeli, izleyici merakta bırakmak için yeteri kadar bilgi sağlamalı ve değerli saniyeleri çok iyi kullanmalıdır çünkü izleyici başka bir kanala geçebilir (White \& Barnas, 2010: 131). Kam spiker haberi yapılan olayların en önemli unsuruyla açıkça ilişkilendirilecek ayrıntıların en azını içerir. Kam spikeri kısa ve basit tutabilmek için, tarih ve diğer bağlamlar sonraki paragraflara bırakılmalı (Fang, 1991). Klasik veya geleneksel kam spiker 12 ila 20 sözcük uzunluğundaki bir giriş cümlesinden sonra izleyiciyi en çok etkileyecek unsurlarla devam eder ama tüm haberi anlatma girişiminde bulunmaz (Thompson, 2005: 101).

Bir kam spikerin uzunluğu, onu takip edecek haberin uzunluğuyla orantılı olmalıdır. ITN'nin haberlerinde standart olan 1 dakika 40 saniyelik haberin kam spikeri 25 saniye olabilirken BBC Newsnight'taki 6 dakikalık bir videonun kam spikeri yaklaşık bir dakikalık uzunluğa ulaşabilir (Thompson, 2005: 103).

Yazılı basında haber giriş türlerine ilişkin çeşitli sınıflandırmalar vardır. Tokgöz haber girişi sınıflandırmasını şekil bakımından (tek olaylı giriş / çok olaylı giriş), $5 \mathrm{~N} 1 \mathrm{~K}$ kuralı bakımından (yani bu sorulardan birinin öne çıkarıldığı giriş 
çeşitleri) ve üslup bakımından (doğrudan doğru anlatımlı giriş / dolaylı anlatımlı giriş / kapalı giriş / yı̆̆ma giriş / hikaye girişi / alıntıll giriş / sorulu giriş / olumsuz giriş / flaş giriş) yapmaktadır (Tokgöz, 1994: 187-195). Televizyon haberlerinin kam spiker türleriyle ilgiliyse literatürde farklı sınıflandırmalar bulunmaktadır. Türkçe literatürde en ayrıntılı sınıflandırma Kemal Aslan (2002) tarafından yapılmıştır. Aslan, Kam Spikerleri; 1) şekil bakımından, 2) 6N1K kuralı bakımından, 3) dil bakımından, 4) üslup bakımından sınıflandırır. Şekil Bakımından yapılan sınıflandırmada tek mesajlı ve açımlamalı kam spiker vardır (Aslan, 2002: 150-156). 6N1K (Aslan habercilik sorularına "nereden"i de eklemektedir.) kuralı bakımından yapılan sınıflandırmada bu sorulardan birinin öne çıktığı kam spiker türleri (kim ile yapılan kam spiker, ne ile yapılan kam spiker vb.) siralanmaktadır (Aslan, 2002: 162-171). Dil bakımından yapılan sınıflandırmada geçişli fiillerle, geçişsiz fiillerle, etken fiillerle ve edilgen fiillerle yapılan kam spiker türleri vardır (Aslan, 2002: 172173). Üslup bakımından ise alıntıll, klyaslamall, durum odakl, kaynak odakl, olay odakl, atasözüyle yapılan, deyimle yapılan, soru sorarak yapılan, tanımla yapılan ve karma kam spiker türleri bulunmaktadır (Aslan, 2002: 172-177).

Bu çalışmadaysa bu kadar detaylı bir kam spiker sınıflandırması yerine daha geniş başlıklara dayanan bir sınıflandırma seçilmiştir: "hard lead", "soft lead" ve "quote lead" (White \& Barnas, 2010). "Hard lead" haberin ayrıntılarını izleyiciye derhal söyler. "Soft lead" izleyiciyi 1sitır, haber videosuna ilgi ve merak duymasinı sağlar. Bazen de bir alıntı, haber videosu için iyi bir kanca oluşturabilir ve bu durumda "quote lead" yani alıntılı kam spiker seçilebilir (White and Barnas, 2010: 134-135). Hard lead tarzında yazılan kam spikerde dolgulara yer yoktur. Bilgi güçlü etkiyle verilmeli ve ilk cümlesiyle birlikte izleyiciyle bağ kurmalıdır (Boyd, 2001: 68) Quote lead' in Türkçe karşılı̆̆ olarak alıntılı kam spiker denilebilir. Hard lead ve soft lead içinse tek sözcüklük Türkçe karşıllk bulmak güçtür. Ama sözü edilen kam spiker türlerinin özellikleri dikkate alındığında "hard lead" için "doğrudan ve sert girişli kam spiker"; "soft lead" için "dolaylı ve merak uyandıran kam spiker" denilebilir. Tablo 1'de geçmiş gündemli bir uluslararası politika haberinin sunulabileceği 3 kam spiker örneği yer almaktadır. 
Tablo 1: Aynı Habere Farklı Kam Spiker Seçenekleri ve Özellikleri

\begin{tabular}{|c|c|c|}
\hline Haberin Ham Bilgisi & Kam Spiker Türü & $\begin{array}{l}\text { Kam Spiker Türünün } \\
\text { Özellikleri }\end{array}$ \\
\hline \multirow{3}{*}{$\begin{array}{l}\text { İran, Birleşmiş Milletler'den, } \\
\text { ABD'nin durmadan İran'a saldırı } \\
\text { tehdidinde bulunmasını önlemesini } \\
\text { istedi. İran Resmi Ajansı IRNA'nın } \\
\text { haberine göre, İran'ın BM Daimi } \\
\text { Temsilcisi Cevad Zarif, BM Genel } \\
\text { Sekreteri Kofi Annan'a gönderdiği } \\
\text { mektupta, ABD'li yetkililerin } \\
\text { "yasadışı ve pervasız" tehditlerine } \\
\text { karşı derhal önlem alınmasını } \\
\text { istediklerini bildirdi. Mektupta, } \\
\text { "Birleşmiş Milletler'in geçmişte bu } \\
\text { yasadışı ve haksız tehditlere yanıt } \\
\text { vermedeki ihmalkarlığı üzüntü } \\
\text { vericidir. Bu tutum, üst düzey } \\
\text { ABD'li yetkililerin daha da küstah } \\
\text { olmalarına ve hatta bir seçenek } \\
\text { olarak nükleer silah kullanmayı } \\
\text { düşünmelerine yol açmıştır" denildi. } \\
\text { Zarif, mektubunda, bazı üst düzey } \\
\text { ABD'li yetkililerin, temelsiz } \\
\text { bahanelerle İran'a karşı güç kullanma } \\
\text { tehdidinde bulunmak suretiyle, } \\
\text { uluslararası hukuku ve BM } \\
\text { sözleşmesinin temel ilkelerini } \\
\text { çiğnediklerini savundu. }\end{array}$} & $\begin{array}{l}\text { Hard Lead (Doğrudan ve sert girişli } \\
\text { kam spiker): } \\
\text { İran, Birleşmiş Milletler'den, ABD'nin } \\
\text { ülkesine yönelik saldırı tehditlerini } \\
\text { önlemesini istedi. İran'ın, Birleşmiş } \\
\text { Milletler Genel Sekreteri Kofi Annan'a } \\
\text { gönderdiği mektupta, uluslararası } \\
\text { hukukun çiğnendiği belirtildi. İran, } \\
\text { BM'nin ihmalkarlığıyla, ABD'nin giderek } \\
\text { daha küstahlaştığını öne sürdü. }\end{array}$ & $\begin{array}{l}\text { Doğrudan giriş yapıyor. } \\
\text { Haberin en önemli } \\
\text { kısımlarıyla başlıyor. } \\
\text { 5N1K konusunda } \\
\text { cömert davranıyor } \\
\text { (makul televizyon } \\
\text { cümlesi uzunluğunu } \\
\text { aşmamak kaydıyla). }\end{array}$ \\
\hline & $\begin{array}{l}\text { Soft Lead (Dolaylı ve merak uyandıran } \\
\text { kam spiker): } \\
\text { İran'dan Birleşmiş Milletler'e tepki } \\
\text { mektubu... Genel Sekreter Kofi Annan'a } \\
\text { gönderilen mektupta, ABD'nin saldırı } \\
\text { tehditleri ele alındı. İran'ın eleştiri okları } \\
\text { hem ABD'ye hem de BM'ye yöneldi. (Ya } \\
\text { da: Bakın İran, ABD ve BM'yi neyle } \\
\text { suçladı?) }\end{array}$ & $\begin{array}{l}\text { Dolaylı giriş yapıyor. } \\
\text { 5N1K konusunda cimri } \\
\text { davranıyor. Haberi ima } \\
\text { ediyor, izleyiciyi } \\
\text { 1sıtıyor, merak } \\
\text { uyandırıyor ve merakın } \\
\text { giderilmesini videoya } \\
\text { bırakıyor. }\end{array}$ \\
\hline & $\begin{array}{l}\text { Quote Lead (Alıntılı kam spiker): } \\
\text { “Birleşmiş Milletler'in tutumu ABD’nin } \\
\text { daha da küstah olmasına yol açıyor.” } \\
\text { İran'ın Birleşmiş Milletler'e gönderdiği } \\
\text { mektupta bu ifade yer aldı. İran, Birleşmiş } \\
\text { Milletler'den, ABD'nin saldırı tehditlerini } \\
\text { önlemesini istedi. }\end{array}$ & $\begin{array}{l}\text { Çarpıcı bir alıntıyla } \\
\text { başlıyor, hemen ikinci } \\
\text { cümlede bu sözlerin } \\
\text { kime ait olduğunu } \\
\text { belirtiyor ve son bir } \\
\text { cümleyle bitiriyor }\end{array}$ \\
\hline
\end{tabular}

Thompson, 'dolaylı ve merak uyandıran kam spiker'e yakın bir tanımlamayla nitelendirdiği kam spiker türünü davetkar kam spiker olarak adlandırır. Haberin daha ilk cümlede özetlendiği klasik kam spikerlere göre daha yaratıcı bir yaklaşım sergileyen, daha sohbete dayalı ve davetkar olan bu eğilim daha çok ABD yayıncılığına yöneliktir (Thompson, 2005: 101). Davetkar kam spikerde bazen dikkat çekmek ve izleyici ile haber arasında bağ oluşturabilmek için sorular işe yarayabilir. Örneğin "Çocuklarınızın uyuşturucu kullanıyor olabilecekleri sizi endişelendiriyor mu? Gençlerle yapılan bir araştırmaya göre ergenlik çağındaki her üç çocuktan ikisi uyuşturucuyla karşılaşlyor...” (Thompson, 2005: 106) şeklindeki bir kam spiker ebeveynlerin habere olan ilgisini daha ilk cümleden yükseltmiş olur.

Boyd ise 'dolaylı ve merak uyandıran kam spiker'e yakın bir girişi "feature opener" olarak tanımlar: Haberin özünün ilk cümlede verilmesi yerine izleyicinin duygularına hitap ederek, onları haberin içine çeken bir üslup (Boyd, 2001: 73). Örneğin: "Eğer ürkütücü sürüngenlerle ilgili korkunuz varsa ve bir yılanın üstüne basma düşüncesi bile sizi hasta ediyorsa, o zaman Canberra'dan Jeb Winston için bir an durun ve düşünün. Jeb'in etrafi yılanlarla sarılacak ... Bunların birçoğu zehirli ... Bunu iki hafta boyunca sürdürecek. Jeb, dünya yılanlarla oturma rekorunu kırmaya hazırlaniyor." (Boyd, 2001: 73).

Hangi türde kam spikerin kullanılacağının kararı bir dizi faktöre bağlıdır: Özel bir haber mi flaş bir haber mi; haber üzücü mü sevindirici mi; insanlarla mı 
yoksa bir olayla mı ilgili; haber, siyasetle mi, savaşla mı yoksa tıbbi bir gelişme veya bir çocuğun kaçırılmasıyla mı ilgili; haber yeni bir gelişme mi devam eden bir gelişme mi (White \& Barnas, 2010: 131)? Hangi durumda hangi tür kam spikerin kullanılacağına dair kesin ve belirleyici bir kural arayışına girmek editoryal karar süreçlerinin doğasına aykırı kaçabilir. Yine de belli durumlarda hangi kam spiker türünü kullanma eğiliminin daha öne çıkabileceğine ilişkin tespit ve öngörülerde bulunulabilir.

Flaş bir gelişmeyi aktarırken 'doğrudan ve sert girişli kam spiker' kullanılması mantıklıdır. Örneğin trajedilerle ilgili haberler: "Meksika'daki depremde ölenlerin sayısının 50'yi aştı̆̆ belirtiliyor." Ancak insani ilgi haberlerinde ve son dakika niteliği taşımayan gelişmelerde kam spiker seçiminde daha esnek davranılabilir (White \& Barnas, 2010: 133-134). Haber bülteninde bir muhabirin canlı bağlantıyla aktaracağı haberin kam spikerinde sunucular çoğunlukla 'dolaylı ve merak uyandıran kam spiker' kullanır: "Yeni futbol stadyumunun nereye yapılacağlyla ilgili haftalar süren görüşmeler bugün öğleden sonra sona erdi. Ayrıntılar Bill Winter'da...” (Fang, 1991). Hangi kam spiker türünün kullanılacağ 1 bazen de haberin bültendeki ya da haber programındaki sırasına göre bile değişebilir. Programın başındaki ciddi, trajik veya endişe veren haberlerin kam spikerleriyle çok fazla oynanamazken sonlara doğru editörler izleyiciyi daha angaje eden bir tarz kullanabilir (Thompson, 2005: 105-106). Bu bölümde yer alan haberler için daha rahat ve gayriresmi bir yaklaşım sergilenebilir (Boyd, 2001: 73).

Kam spiker türlerinin bir bülten içinde ne oranda kullanılacağı televizyon kanalının türüne de bağlı olabilir. Genel televizyon kanallarındaki izlenme oranı yarışı, haber kanallarındakine göre daha sert geçer. Ayrıca genel televizyon kanallarının izleyici kitlesinin sosyoekonomik statü grupları haber kanallarınınkinden farklılık gösterebilir. Genel televizyon kanalları haberi aktarırken haber kanallarına göre hikayeleştirmeye daha çok başvurabilirler. $\mathrm{Bu}$ ve benzeri unsurlar nedeniyle genel televizyon kanallarının ana haber bültenlerinde tematik haber kanallarınınkine oranla daha fazla 'dolaylı ve merak uyandıran kam spiker' kullanımı görülebilir.

\section{YÖNTEM}

Bu çalışmada Türkiye'de genel TV kanalları ile tematik haber kanalları arasında kam spiker türü tercihi ve kullanım ağırlığı, nicel içerik analizi yöntemiyle karşılaş̧ırmalı olarak incelenmiştir. Çalışmanın evreni Türkiye'de ulusal çapta yayın yapan ve ana haber kuşağı rekabetinde varlık gösteren genel TV kanalları (Fox, atv, Show, Star, Kanal D, TRT1) ve ulusal çapta yayın yapan ve Digitürk ve D-Smart gibi popüler yayın platformlarında izlenebilen haber kanallarıdır (Habertürk, CNNTürk, NTV, ahaber, TRT Haber, TGRT Haber, Ülke TV, TV Net, Haber Global). Çalışmanın sınırlılıkları açısından bu evren içinden 3 genel ve 3 haber kanalı seçilmiş ve bu kanalların 3 günlük ana haber bültenleri incelenmiştir. Genel TV kanalları olarak Show, Star ve atv; haber kanalları olarak da NTV, Haber Global 
ve Habertürk'ün 7 Ocak - 9 Ocak 2019 arasındaki 3 günlük ana haber bültenlerinin içerik analizi yapılmıştır. Bültenlerdeki bütün haberlerin kam spikerleri, türlerine göre (hard, soft veya quote) sinıflandırılmıştır. Ayrıca bu kam spikerlerle duyurulan haberler de türlerine göre tasnif edilmiş ve belli türdeki haberlerin belli türde kam spikerlerle duyurulduğu yönünde editoryal bir eğilim olup olmadığı araştırılmıştır.

\section{BULGULAR}

Örneklemdeki kanalların Habertürk hariç hepsinde ana haber bülteni 19.00 'da başlamakta ve içindeki reklamlarla birlikte yaklaşık 1 saatlik bir yayın dilimini doldurmaktadır. Habertürk ana haber bülteni ise 19.00 'da başlamakla birlikte içinde reklam ve başka yayın kuşaklarıyla birlikte yaklaşık 2 saat sürmektedir. Bültenin 20.00'de başlayan kısmında ilk dilimde yayımlanan bazı haberler (çok az sayıda da olsa) aynen veya değiştirilerek tekrar yayımlanmaktadır. Örneğin 7 ve 8 Ocak'ta Habertürk ana haber bülteninin ilk diliminde (19.00-20.00) yayımlanan 5'er haber, bültenin ikinci diliminde de (20.00-21.00) yayımlanmıştır. Örneklemdeki kanalların 3 günlük ana haber bültenlerinin analizinde 259'u genel kanallarda 331'i haber kanallarında olmak üzere toplam 590 haber incelenmiştir. $\mathrm{Bu}$ sayının kanallara göre dağılım Tablo 2'de görülmektedir. Habertürk ana haber bülteninin sadece 19.00-20.00 arası olan kısmı dikkate alınsaydı bu kanalın üç günlük toplam haber sayıs1 90 olacaktı.

Tablo 2: Örneklemdeki Kanalların Ana Haber Bültenlerindeki Haber Sayısı

\begin{tabular}{|l|l|c|c|c|}
\hline & & 7 Ocak & 8 Ocak & 9 Ocak \\
\hline \multirow{3}{*}{ Genel Kanallar (259) } & Show (117) & 39 & 41 & 37 \\
\cline { 2 - 5 } & Atv (64) & 22 & 19 & 23 \\
\cline { 2 - 5 } & Star (78) & 25 & 28 & 25 \\
\hline \multirow{3}{*}{ Haber Kanalları (331) } & NTV (91) & 30 & 26 & 35 \\
\cline { 2 - 5 } & Habertürk (147) & 49 & 51 & 47 \\
\cline { 2 - 5 } & Haber Global (93) & 30 & 29 & 34 \\
\hline
\end{tabular}

590 haberin kam spikerleri türlerine ayrılmıştır. Bazı kam spikerler için bu ayrım çok net yapılabilmiştir. Bazı kam spikerlerinse bu sınıflandırmadaki kam spiker türlerinin herhangi birinin bütün karakteristiklerini yansıtmadığı görülmüştür. $\mathrm{Bu}$ durumda en yakın durdukları kategoriler tercih edilmiştir. Kam spiker türlerine tipik olarak uyan ve yakın duran metin örnekleri Tablo 3'te verilmiştir. 
Tablo 3: Kam Spiker Türü Sınıflandırması: Tipik ve Yakın Örnekler

\begin{tabular}{|c|c|}
\hline \multicolumn{2}{|c|}{ Hard (Doğrudan ve sert girişli kam spiker) } \\
\hline Tipik & Yakın \\
\hline ADALET VE KALKINMA PARTİSI MECLİS & AL MEDYAYA BAKINIRKEN TEHLİKE \\
\hline BAŞKANLIĞINA 18 MADDELİK TORBA & VAR AMA SOSYAL MEDYA İÇİN BAKINIRKEN \\
\hline KANUN TEKLİFİ SUNDU. TEKLİF, PERSONEL & DAHA BÜYÜK TEHLIKKE VAR! DENIZZLİ'DE \\
\hline SAYISI 500’ÜN ÜZERINDDE OLAN İŞ & SEYİR TEPESİNE ÇIKAN BİR GENÇ, SELFIE \\
\hline YERLERINNE 150, ÜSTÜNDE OLANLARAYSA & ÇEKMEK İSTERKEN AŞAĞI DÜŞTÜ. BACAĞI \\
\hline 100 LIRA ASGARİ ÜCRET DESTEĞİ & KIRILAN TALİHSIZZ GENÇ, DONMAK \\
\hline VERILMESINII ÖNGÖRÜYOR. EV & ÜZEREYKEN KURTARILDI. (Show Ana Haber \\
\hline KADINLARININ ÜRETIP SATTIĞI ÜRÜNLERE & Bülteni, 8 Ocak 2019) \\
\hline $\begin{array}{l}\text { DE VERGİ MUAFIYETİ GETİRILIYYOR (Habertürk } \\
\text { TV Ana Haber Bülteni, } 9 \text { Ocak 2019) }\end{array}$ & \\
\hline \multicolumn{2}{|c|}{ Soft (Dolaylı ve merak uyandıran kam spiker) } \\
\hline Tipik & Yakın \\
\hline MECLİS ÇATISI ALTINDA BUGÜN DE KAVGA & İNATÇI TÜKETİĊ, BOZULAN BULAŞIK \\
\hline VARDI. CUMHURBAȘKANI ERDOĞAN ŞEREF & MAKİNESİ İÇİN MAHKEMEDEN EMSAL BİR \\
\hline HOLÜNDE PARTİLILERLE SOHBET EDERKEN & KARAR ALDIRDI. FIRMA, "GARANTİ SÜRESİ \\
\hline KORUMALARI GİRISSLERİ KAPATTI. TAM O & DOLDU" DIYYEREK TAMİRE YANAŞMAMIŞTI \\
\hline SIRADA DA HDP'Lİ VEKİLLER GRUP & ANCAK MAHKEME, "MAKINENIN PARASI \\
\hline TOPLANTISINI TAMAMLAMIŞ, HOLE & FAİZIYLE BİRLİKTE ÖDENSİN" DEDİ. \\
\hline ÇIKMIŞTI. İŞTE O AN ORTALIK KARIŞTI. (Star & DEDİĞİMİZ GİBİ KARAR HERKESİ ÇOK \\
\hline Ana Haber Bülteni, 8 Ocak 2019) & YAKINDAN İLGILENDİRIYOR, BAKIN HANGİ \\
\hline & $\begin{array}{l}\text { GEREKÇEYLE? (atv Ana Haber Bülteni, } 7 \text { Ocak } \\
\text { 2019) }\end{array}$ \\
\hline \multicolumn{2}{|c|}{ Quote (Alıntılı kam spiker) } \\
\hline Tipik & Yakın \\
\hline "ÖLEN KADINLARDAN BİRİ OLMAK & ABD BAŞKANI DONALD TRUMP SURIYYE'DEN \\
\hline İSTEMIYORUM". BU İÇ ACITAN CÜMLEYİ & ÇEKİLMEYLE İLGILİ YENİ BİR AÇIKLAMA \\
\hline KURAN KADIN YILLARCA ȘIDDET GÖRDÜ. & YAPTI. TRUMP, "ÇEKILME PLANINDA \\
\hline SONUNDA DAYANAMAYIP BABASININ EVINE & DEĞİŞIKLLIKK YOK " DEDİ. (Haber Global Ana \\
\hline SIĞINDI. AMA EŞİM, ÇOCUKLARIMIN BABASI & Haber Bülteni, 7 Ocak 2019) \\
\hline DEDIĞİ ADAM, ORADA DA RAHAT & \\
\hline BIRAKMADI. HAY ATINI CEHENNEME & \\
\hline ÇEVİRDİ. (Show Ana Haber Bülteni, 8 Oc & \\
\hline
\end{tabular}

Tablo 3'teki gibi bir yol izlenerek 590 haberin kam spikeri sınıflandırılmış ve hangi kam spiker türünün ne ağırlıkta kullanıldığı yüzde olarak hesaplanmıştır. Çıkan sonuçlar Tablo 4'te listelenmektedir. Tablo 4'teki veriler bir de genel kanallar/haber kanalları olarak oluşturulmuştur. Bu yapılırken her iki kategoriye giren 3'er kanalın bültenlerindeki kam spiker türü ağırlığının ortalamaları hesaplanmıştır. Çıkan sonuçlar Grafik 1'de yer almaktadır.

Tablo 4: Örneklemdeki Kanalların Ana Haber Bültenlerindeki Kam Spiker Türü Oranlar1

\begin{tabular}{|c|c|c|c|c|c|c|c|c|c|c|}
\hline & & \multicolumn{3}{|c|}{7 Ocak } & \multicolumn{3}{|c|}{8 Ocak } & \multicolumn{3}{|c|}{9 Ocak } \\
\hline & & Hard & Soft & Quote & Hard & Soft & Quote & Hard & Soft & Quote \\
\hline \multirow{3}{*}{$\begin{array}{l}\text { Genel } \\
\text { Kanallar }\end{array}$} & Show & $\% 28$ & $\% 72$ & - & $\% 22$ & $\% 63$ & $\% 15$ & $\% 38$ & $\% 51$ & $\% 11$ \\
\hline & Atv & $\% 46$ & $\% 50$ & $\% 4$ & $\% 21$ & $\% 58$ & $\% 21$ & $\% 36$ & $\% 55$ & $\% 36$ \\
\hline & Star & $\% 76$ & $\% 24$ & - & $\% 54$ & $\% 43$ & $\% 3$ & $\% 64$ & $\% 36$ & - \\
\hline \multirow{3}{*}{$\begin{array}{l}\text { Haber } \\
\text { Kanalları }\end{array}$} & NTV & $\% 70$ & $\% 30$ & - & $\% 50$ & $\% 50$ & - & $\% 60$ & $\% 34$ & $\% 6$ \\
\hline & Habertürk & $\% 72$ & $\% 20$ & $\% 8$ & $\% 82$ & $\% 8$ & $\% 10$ & $\% 72$ & $\% 21$ & $\% 7$ \\
\hline & $\begin{array}{l}\text { Haber } \\
\text { Global }\end{array}$ & $\% 82$ & $\% 18$ & - & $\% 59$ & $\% 34$ & $\% 7$ & $\% 62$ & $\% 29$ & $\% 9$ \\
\hline
\end{tabular}


Örneklemde en yüksek 'dolaylı ve merak uyandıran kam spiker' kullanım oranı \%62 ortalamayla Show televizyonunun ana haber bültenindedir. Bu sayı atv ana haber bülteni için \%54, Star ana haber bülteni için \%34'tür. Genel kanalların ortalama 'dolaylı ve merak uyandıran kam spiker' kullanım oranı \%51 iken haber kanallarında bu oran \% 27'ye düşmektedir. Buna karş11ık haber kanallarında ortalama 'doğrudan ve sert girişli kam spiker' kullanım oranı \%68 iken genel kanallarda bu oran \%43'e düşmektedir. Alıntılı kam spiker kullanımı oranı açısından genel kanallar ile haber kanalları arasında belirgin bir fark yoktur.

Grafik 1: Örneklemdeki Genel Kanalların ve Haber Kanallarının Ana Haber Bültenlerinde Kullandıkları Kam Spiker Türleri Oranları

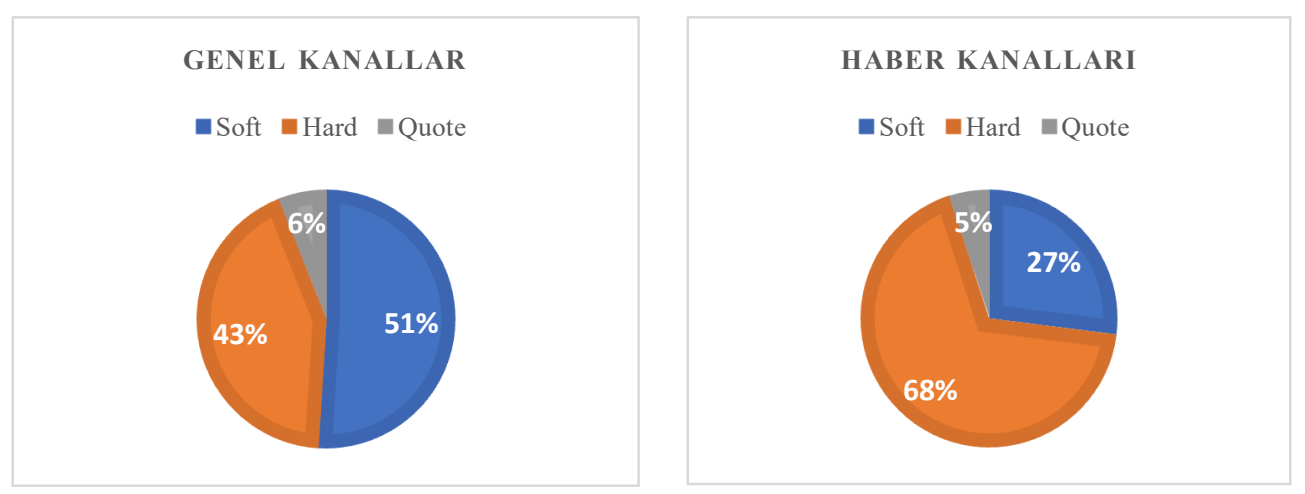

Çalışmada haber türleri ile kam spiker türleri arasındaki ilişki de incelendi. Aslında her türlü haber 3 farklı kam spiker türünden herhangi birinde sunulabilir. Ama editörlerin belli haber türlerinde daha çok yöneldikleri bir kam spiker türü olabilir. Böyle bir eğilim olup olmadığını ortaya çıkarmak için örneklemdeki 590 haber, türlerine göre sınıflandırıldı. Örneklemdeki 590 haber incelendikten sonra yapılan sınıflandırmanın detayları Tablo 5 'te gösterilmektedir.

Tablo 5: Haber Türleri Sınıflandırması ve Türlerin Kapsamları

\begin{tabular}{|l|l|}
\hline Haber Türü & Türün Kapsama Alanı \\
\hline İç siyaset & $\begin{array}{l}\text { Partilerin faaliyetleri, seçim kampanyaları, seçimle ilgili gelişmeler, siyasilere yönelik davalar, grup } \\
\text { konuşmaları, siyasilerin demeçleri ve polemikleri, siyasi davalar, ifade özgürlüğ̈ davaları vb. }\end{array}$ \\
\hline Dış siyaset & Türk dış siyaseti, Türkiye’yi ve yakın coğrafyasını doğrudan ilgilendiren uluslararası siyaset vb. \\
\hline Polis adliye & $\begin{array}{l}\text { Güvenlik operasyonları, cinayet, hırsızlık, soygun, şiddet, hayvanlara kötü muamele, trafik kazaları, } \\
\text { yangınlar, çökme, enkaz, kurtarma çalışmaları vb. }\end{array}$ \\
\hline Ekonomi & $\begin{array}{l}\text { Makroekonomik kararlar, bütçe idaresi, teşvik paketleri, mikroekonomik gelişmeler, yakıt, enerji, } \\
\text { konut, gıda fiyatları, ev kiraları, köprü geçiş ücretleri, kredi kartı borçları, tüketici hakları, çalışma } \\
\text { hayatı, kıdem tazminatı, iş başvuruları, grev vb. }\end{array}$ \\
\hline Dünya & $\begin{array}{l}\text { Dünyanın çeşitli noktalarında yaşanan gelişmeler, eylemler, çatışmalar, darbeler, festivaller, ilginç } \\
\text { insan öyküleri vb. }\end{array}$ \\
\hline Sağlık & Halk sağlığı, obezite, sağlık skandalları, bebek ölümleri, grip, zayıflama, gıda güvenliği vb. \\
\hline Hava & Kar, sağanak gibi olumsuz hava koşullarının yaşam üzerindeki etkileri. \\
\hline İnsani ilgi & $\begin{array}{l}\text { Teknoloji, örnek yardımlaşmalar, köpeği kaybolan bir turist, çarpıcı organ nakli hikayeleri, kedi } \\
\text { besleyen öğrenciler, ev kiralayan köpekler, ilginç bilgisayar oyunları, ilginç sosyal medya vakaları, } \\
\text { hayvan kurtarma operasyonları, kardan adama saldıran adamlar, annesinin sesini ilk kez işiten } \\
\text { bebek, ünlülerin dünyası, vizyona giren filmler vb. }\end{array}$ \\
\hline Habcte ve dış̧a çeşitli haberlerden derlenen turlar. \\
\hline
\end{tabular}


Bu sinıflandırmanın ardından örneklemdeki bütün kanalların toplam 590 haberi için, hangi haber türünde hangi kam spiker türünün ne oranda kullanıldığ 1 Tablo 6'da yer almaktadır. 590 haber içinde sadece 7 adet var olan ve hepsi 'dolaylı ve merak uyandıran kam spiker'le duyurulan haber turları bu tabloya dahil edilmemiştir. En yüksek 'dolaylı ve merak uyandıran kam spiker' kullanımı \%65'le insani ilgi haberlerinde, en yüksek 'doğrudan ve sert girişli kam spiker' kullanımı \%76'yla hava koşulları haberlerinde ve en yüksek 'alıntılı kam spiker' kullanımı \%34'le dış siyaset haberlerinde görülmüsstür. 'Dolaylı ve merak uyandıran kam spiker' in \%60'ın üzerinde baskın kullanıldığı başka bir haber türü yoktur. 'Doğrudan ve sert girişli kam spiker'in ise \%60' ın üzerinde baskın kullanıldığı diğer haber türleri ekonomi ve polis adliyedir. Tüm haber türleri içinde kullanım oranı nispeten çok düşük olan 'alıntılı kam spiker' en çok diş ve iç siyaset haberlerinde kullanılmıştır. $\mathrm{Bu}$ da, bu kam spiker türünü etkin bir şekilde kullanabilmek için eldeki haber materyalinde çarpıcı bir beyan olması gerekliliğiyle uygun çıkmıştır.

Tablo 6: Örneklemdeki Tüm Kanalların, Haber Türleri Sınıflandırmasına Göre Ana Haber Bültenlerinde Kullandıkları Kam Spiker Türlerinin Oranı

\begin{tabular}{|l|c|c|c|}
\hline Haber Türü & Hard & Soft & Quote \\
\hline İnsani ilgi & $\% 35$ & $\% 65$ & - \\
\hline Dış siyaset & $\% 47$ & $\% 19$ & $\% 34$ \\
\hline Sağlik & $\% 48$ & $\% 52$ & - \\
\hline Dünya & $\% 56$ & $\% 44$ & - \\
\hline İç siyaset & $\% 59$ & $\% 24$ & $\% 17$ \\
\hline Polis adliye & $\% 63$ & $\% 34$ & $\% 3$ \\
\hline Ekonomi & $\% 71$ & $\% 29$ & - \\
\hline Hava & $\% 76$ & $\% 24$ & - \\
\hline
\end{tabular}

Örneklemdeki genel kanalların ve haber kanallarının hangi haber türlerinde hangi kam spiker türünü ne oranda kullandığına dair bir karşılaştırma da yapılmıştır. Sonuçlar Grafik 2'de görselleştirilmiştir. 590 haber içinde sadece 7 adet var olan ve hepsi 'dolaylı ve merak uyandıran kam spiker'le duyurulan haber turları bu grafiğge dahil edilmemiştir. 
Grafik 2: Haber Türlerine Göre Örneklemdeki Genel Kanalların ve Haber Kanallarının Ana Haber Bültenlerinde Kullandıkları Kam Spiker Türleri Oranları
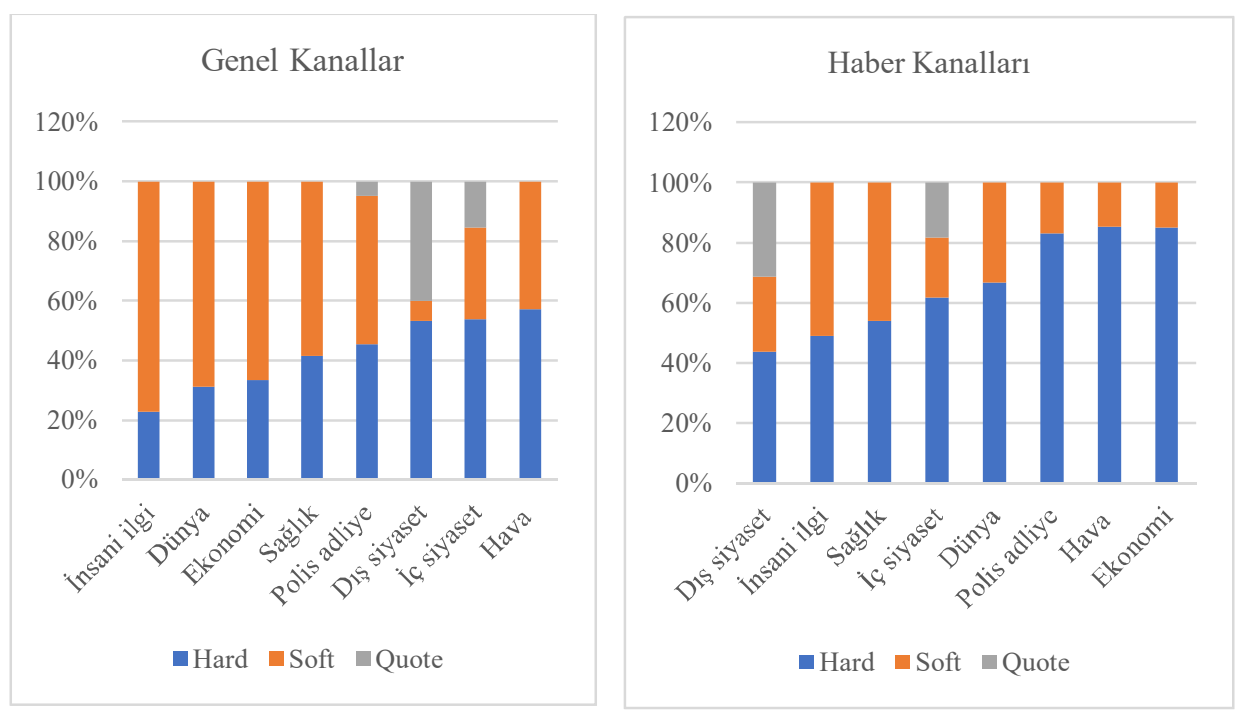

Genel kanalların ortalama 'dolaylı ve merak uyandıran kam spiker' kullanım oranı $\% 51$ 'dir. Bu ortalama değerin üzerinde bir oranla 'dolaylı ve merak uyandıran kam spiker' kullanılan haber türleri şöyle sıralanmaktadır: insani ilgi (\%77), dünya $(\% 69)$, ekonomi (\%67) ve sağlı (\%58). Haber kanallarında ortalama 'dolaylı ve merak uyandıran kam spiker' kullanım oranı $\% 27$ 'dir. Bu ortalama değerin üzerinde bir oranla 'dolaylı ve merak uyandıran kam spiker' kullanılan haber türleri şöyle sıralanmaktadır: insani ilgi (\%51), sağlık (\%46) ve dünya (\%33).

Genel kanalların ortalama 'doğrudan ve sert girişli kam spiker' kullanım oranı \% 43 'tür. Bu ortalama değerin üzerinde bir oranla 'doğrudan ve sert girişli kam spiker' kullanılan haber türleri şöyle sıralanmaktadır: polis adliye (\%46), diş siyaset $(\% 53)$, iç siyaset $(\% 54)$ ve hava koşulları $(\% 57)$. Haber kanallarında ortalama 'doğrudan ve sert girişli kam spiker' kullanım oranı \%68'dir. Bu ortalama değerin üzerinde bir oranla 'doğrudan ve sert girişli kam spiker' kullanılan haber türleri şöyle sıralanmaktadır: ekonomi (\%85), hava koşulları (\%85) ve polis adliye $(\% 83)$.

\section{SONUÇ}

Kullanımlar ve doyumlar kuramına göre yapılan pek çok araştırma insanların televizyonda hangi ihtiyaçlarını doyuma ulaştırdıklarına dair sonuçlar ortaya çıkarmıştır. Bu konuda belli ölçüde teorik kavrayışa ve büyük ölçüde saha birikimine sahip olan televizyon içerik üreticileri de farkında olarak ya da olmayarak bu ihtiyaçlara hitap eden içerikler üretip izlenme oranı rekabetinde öne çıkmaya çalışmaktadırlar. TV yayıncılığının rekabet kulvarlarının önemli bir ayağını haberler oluşturur. $\mathrm{Bu}$ rekabetin haber bültenlerine biçim ve içerik olarak yansıdığı boyutlardan biri de haberin sunum metnidir. $\mathrm{Bu}$ çalışma izlenme oranlarını 
artırabilmek için haberin daha çarpıcı bir şekilde sunumu eğiliminin Türkiye'de genel televizyon kanalları ile tematik haber kanallarına ne ölçüde yansıdığını karşılaş̧ırmalı olarak araştırmaktadır. Karşılaş̧ırma, televizyonların ana haber bültenlerindeki kam spiker'lerin içerik analizi üzerinden yapılmaktadır.

İzleyicilerin aradıkları doyumları karşılamak için televizyon habercilerinin benimsediği sansasyonel tarz kam spiker türü tercihinde de kendini göstermektedir. Her kam spikerde kaşınan bir merak duygusu, ardından bu merakın giderilmesi ve bu serinin pek çok haber için devam etmesi, izleyicileri, bir gerçekler ve olgular bütününü izlemekten ziyade bir gösteri izleme durumuna sokabilir. Konu televizyon haberciliğinin kalitesi ve haberin izleyicilerle kurduğu ilişkinin nesnellik ve rasyonellik boyutuyla da yakından ilgilidir.

Kam spiker türleriyle ilgili çeşitli detaylı sınıflandırma biçimleri vardır. Ancak bu çalışmada, çalışmanın ortaya çıkarmaya çalıştığı sonuca daha yalın bir şekilde ulaşılmasına katkısı olacağı için White ve Barnas'ın (2000) üçlü sınıflandırması kullanılmıştır: "hard lead" (doğrudan ve sert girişli kam spiker), "soft lead" (dolaylı ve merak uyandıran kam spiker), "quote lead" (çarpıcı bir alıntıyla başlayan kam spiker). "Hard lead" haberin en önemli kısmını ilk cümlede verir, makul televizyon cümlesi uzunluğunu aşmamak kaydıyla $5 \mathrm{~N} 1 \mathrm{~K}$ yanıtları konusunda cömert davranır. "Soft lead" habere dolaylı giriş yapar, 5N1K konusunda cimri davranır, haberi ima eder, izleyiciyi isıtır, merak uyandırır ve merakın giderilmesini videoya bırakır. "Quote lead" ise çarpıcı bir alıntıyla başlayarak izleyiciyi şaşırtır, bu sözlerin kime ait olduğunu gecikmeli olarak bildirir.

Genel televizyon kanallarındaki izlenme oranı yarışı, haber kanallarındakine göre daha sert geçer. Ayrıca genel televizyon kanallarının izleyici kitlesinin sosyoekonomik statü grupları haber kanallarınınkinden farklılık gösterir. Genel televizyon kanalları haberi aktarırken haber kanallarına göre hikayeleştirmeye daha çok başvurabilirler. Bu ve benzeri unsurlar nedeniyle genel televizyon kanallarının ana haber bültenlerinde, tematik haber kanallarınınkine oranla daha fazla 'dolaylı ve merak uyandıran' kam spiker kullanımı görülebilir. Çalışmanın sonuçları bu varsayımı desteklemiştir. Genel TV kanalları olarak Show, Star ve atv; haber kanalları olarak da NTV, Haber Global ve Habertürk'ün 7 Ocak - 9 Ocak 2019 arasındaki 3 günlük ana haber bültenlerindeki toplan 590 haberin içerik analizi yapılmıştır.

Genel kanalların ortalama 'dolaylı ve merak uyandıran kam spiker' kullanım oranı \%51 iken haber kanallarında bu oran \%27 çıkmıştır. Buna karşılık haber kanallarında ortalama 'doğrudan ve sert girişli kam spiker' kullanım oranı \%68 iken genel kanallarda bu oran \%43 olarak gerçekleşmiştir. Alıntılı kam spiker kullanımı oranı açısından genel kanallar ile haber kanalları arasında belirgin bir fark bulunmamıştır.

Çalışmada ayrıca belli haber türlerinde belli kam spiker türü tercih etme yönünde editoryal bir eğilim olup olmadığ 1 da araştırılmıştır. Böyle bir eğilim, 
editörlerin ana haber bültenleri için haber seçimi yaparken, merak uyandıran sunum şekillerine uygun -sansasyonel sunum potansiyeline sahip- türdeki haberleri tercih etmesinin bir işareti olarak da yorumlanabilir. Genel kanallarda ortalama 'dolaylı ve merak uyandıran kam spiker' kullanımının üzerinde bir oranla bu kam spiker türünün tercih edildiği haber türleri; insani ilgi, dünya, ekonomi ve sağlık haberleridir. Haber kanallarında ortalama 'dolaylı ve merak uyandıran kam spiker' kullanım oranının üzerinde bir oranla bu kam spiker türünün tercih edildiği haber türleri; insani ilgi, sağlık ve dünya haberleridir. Genel kanallar ile haber kanallarında 'dolaylı ve merak uyandıran kam spiker’ kullanma eğiliminin güçlendiği haber türleri büyük ölçüde örtüşmektedir.

Genel kanallarda ortalama 'doğrudan ve sert girişli kam spiker' kullanımının üzerinde bir oranla bu kam spiker türünün tercih edildiği haber türleri; polis adliye, dış siyaset, iç siyaset ve hava koşulları haberleridir. Haber kanallarında ortalama 'doğrudan ve sert girişli kam spiker' kullanımının üzerinde bir oranla bu kam spiker türünün tercih edildiği haber türleri; ekonomi, hava koşulları ve polis adliye haberleridir. Genel kanallar ile haber kanallarında 'dolaylı ve merak uyandıran kam spiker’ kullanma eğiliminin güçlendiği haber türleri yarı yarıya örtüşmektedir.

Tüm haber türleri içinde kullanım oranı nispeten çok düşük olan 'alıntılı kam spiker' en çok dış ve iç siyaset haberlerinde kullanılmıştır. Bu da, bu kam spiker türünü etkin bir şekilde kullanabilmek için eldeki haber materyalinde çarpıcı bir beyan olması gerekliliğiyle uygun çıkmıştır.

$\mathrm{Bu}$ çalışma, sektördeki kam spiker türleri kullanımının oranları ile televizyon kanallarının ve haberlerin türleri arasındaki ilişkiyi ortaya çıkarmayı amaçlaması itibarıyla literatüre bir katkı sunmaktadır. Ancak sonuçlarda 7-9 Ocak 2019'daki Türkiye gündeminin ve seçilen kanalların etkisi görülmüş olabilir. Bu ve benzeri çalışmaların farklı tarihlerde farklı kanallarla da yapılması, farklı gündemlerde ve farklı kanallarda da benzer sonuçların ortaya çıkıp çıkmayacağına dair önem taşımaktadır. Ayrıca televizyon haber editörleriyle sormaca ya da görüşme yöntemleriyle yapılacak çalışmalar da kam spiker türü kullanımındaki editoryal eğilimleri daha iyi anlamaya katkı sağlayacaktır.

\section{KAYNAKÇA}

Abrahamsen, J. (10 Ağustos 2017). Lead writing for broadcast news. https://jeanetteabrahamsen.com/2017/08/10/lead-writing-for-broadcast-news/ (Erişim Tarihi: 25.11.2018).

Aslan, K. (2002). Haberin yol haritası. İstanbul: Anahtar Kitaplar.

Boyd, A. (2001). Broadcast journalism: Techniques of radio and television news (fifth edition). Oxford: Focal Press.

Cereci, S. (2001). Televizyonda program yapımı. İstanbul: Metropol. 
Chapman, J. \& Kinsey, M. (2009). Broadcast journalism: A critical introduction. Oxon: Routledge.

Cremer, C. F., Keirstead, P. O. \& Yoakam, R. D. (1996). ENG: Television news (third edition). New York: McGraw-Hill. Adam.

Dileklen, T. (2005). 5N-1K: Televizyon haberciliği. İstanbul: Okumuş

Fang, I. (1991). Writing style differences in newspaper, radio, and television news. Minneapolis: University of Minnesota.

Girgin, A. \& Özay, S. (2013). Haber yazmak (dördüncü basım). İstanbul: Der Yayınları.

Heist, S. (2013). Writing a script. K. Kobré (Ed.), Videojournalism: multimedia storytelling (ss. 173-186). Burlington: Focal Press.

Hyde, S. \& Ibrahim, D. A. (2016). Television and radio announcing (twelfth edition). Oxon: Routledge. Yayınları.

Kapaklı, K. (2010). Televizyon programcılı̆̆ı. Ankara: Gazeteciler Cemiyeti

Kaptan, A. (1999). Radyo TV haberciliği ve metin yazma-röportaj teknikleri. İstanbul: Maltepe Üniversitesi Yayınları.

Karadağ, G. H. (2000). TV haber programcllı̆̆l ve bir örnek: 32.Gün. İstanbul: Etika Yayınevi.

Karadağ, G. H. \& Algül, A. (2018). Kullanımlar ve doyumlar yaklaşımı bağlamında genel televizyon/tematik televizyon izlenme alışkanlıkları. The Turkish Online Journal of Design, Art and Communication, 8(4), 708-724. doi: 10.7456/10804100/010

Kars, N. (2013). Radyo televizyon haberciliği (üçüncü baskl). İstanbul: Derin Yayınlar1.

Katz, E., Gurevitch, M. \& Haas, H. (1973). On the use of the mass media for important things. American Sociological Review, 38(2), 164-181. doi: $10.2307 / 2094393$

Parsa, S. (1993). TV haberciliği ve kuramlarl. İzmir: Ege Üniversitesi İletişim Fakültesi Yayınları.

Postman, N. \& Powers, S. (1996). Televizyon haberlerini izlemek. (A. Tunç, Çev.) İstanbul: Kavram Yayınları. Yayıncilik.

Sağnak, M. (2011). Son dakika: Haberin televizyonlaştırılmast. İstanbul: TB 
Stephenson, A. R., Reese, D. E. \& Beadle, M. E. (2009). Broadcast announcing worktext: A media performance guide (third edition). Burlington: Focal Press.

Telg, R. (2018). News writing for television and radio. Florida: Department of Agricultural Education and Communication. https://edis.ifas.ufl.edu/wc193 (Erişim Tarihi: 11.12.2018)

Thompson, R. (2005). Writing for broadcast journalists. Oxon: Routledge

Tokgöz, O. (1994). Temel gazetecilik. Ankara: İmge.

Trewin, J. (2003). Presenting on TV and radio: An insider's guide. Oxford: Focal Press.

Uğurlu, E. G. (2012). Televizyon yayıncılığında program türlerinin sinıflandırılması. E.G. Uğurlu (Der.), Radyo ve televizyon programcilığının temel kavramları (ss. 44-71). Eskişehir: Anadolu Üniversitesi Yayınları.

Uğurlu, F. \& Öztürk, Ş. (2006). Türkiye'de televizyon haberciliği: Özel TV kanallarının getirdikleri. Konya: Tablet.

Uyguç, U. \& Genç, A. (1998). Radyo televizyon haberciliği (2. baskl). İstanbul: Avcıol Basım Yayın.

Vural, İ. K. (2012). Radyo ve TV haberciliği. E. Yüksel (Ed.) Haber yazma teknikleri (ss. 144-163). Eskişehir: Anadolu Üniversitesi Yayınları.

White, T. \& Barnas, F. (2010). Broadcast news: Writing, reporting and producing (fifth edition). Burlington: Focal Press. 